\title{
Electrochemical inhibition bacterial sensor array for detection of water pollutants: artificial neural network (ANN) approach
}

\author{
Hisham Abu-Ali ${ }^{1,2} \cdot$ Alexei Nabok ${ }^{1} \cdot$ Thomas J. Smith $^{3}$
}

Received: 14 March 2019 /Revised: 1 April 2019 / Accepted: 15 April 2019/Published online: 3 June 2019

(C) The Author(s) 2019

\begin{abstract}
This work reports on further development of an inhibition electrochemical sensor array based on immobilized bacteria for the preliminary detection of a wide range of organic and inorganic pollutants, such as heavy metal salts $\left(\mathrm{HgCl}_{2}, \mathrm{PbCl}_{2}, \mathrm{CdCl}_{2}\right)$, pesticides (atrazine, simazine, DDVP), and petrochemicals (hexane, octane, pentane, toluene, pyrene, and ethanol) in water. A series of DC and AC electrochemical measurements, e.g., cyclic voltammograms and impedance spectroscopy, were carried out on screen-printed gold electrodes with three types of bacteria, namely Escherichia coli, Shewanella oneidensis, and Methylococcus capsulatus, immobilized via poly L-lysine. The results obtained showed a possibility of pattern recognition of the above pollutants by their inhibition effect on the three bacteria used. The analysis of a large amount of experimental data was carried out using an artificial neural network (ANN) programme for more accurate identification of pollutants as well as the estimation of their concentration. The results are encouraging for the development of a simple and cost-effective biosensing technology for preliminary in-field analysis (screening) of water samples for the presence of environmental pollutants.
\end{abstract}

Keywords Electrochemical sensor array $\cdot$ Inhibition biosensor $\cdot$ Immobilized bacteria $\cdot$ Water pollution $\cdot$ Pattern recognition . Artificial neural network (ANN)

\section{Introduction}

Nowadays, water pollution caused by the presence of any chemicals in fresh- and seawater which reduce the water quality and affect living organisms in the aquatic environment has become a major problem associated with areas of intensive industry and agriculture. A significant part of

Published in the topical collection New Developments in Biosensors with guest editors Francesco Baldini and Maria Minunni.

Electronic supplementary material The online version of this article (https://doi.org/10.1007/s00216-019-01853-8) contains supplementary material, which is available to authorized users.

Alexei Nabok

a.nabok@shu.ac.uk

1 Materials and Engineering Research Institute, Sheffield Hallam University, City Campus, Paternoster Row, Sheffield S1 1WB, UK

2 Faculty of Science, Department of Biology, University of Basrah, Basrah 61004, Iraq

3 Biomolecular Research Centre, Sheffield Hallam University, City Campus, Sheffield S1 1WB, UK water contamination comes from transport, heavy industry, petrochemical industry, and agricultural activities which release large numbers of toxic chemicals, particularly heavy metals, pesticides, and petrochemicals, in the atmosphere and aquatic environment. Typical petrochemical contaminants are hydrocarbons, alcohols, ketones, benzene derivatives (or BTEX), etc. Considering the adverse effects of the above pollutants on humans, animals, and wildlife, the environmental agencies and World Health Organization set quite low limits (from 0.1 to $0.5 \mathrm{mg} / \mathrm{l})$ for heavy metals $(\mathrm{Hg}, \mathrm{Pb}$, and $\mathrm{Cd})$, pesticides (DDT, DDE, TDE, etc.), and some petrochemical (i.e., methyl alcohol and BTEX) pollutants in drinking water, food, and feed [1]. Worldwide environmental legislation clearly indicates the need for reliable environmental monitoring methods, which are also fast, portable, and costeffective [2]. Therefore, the determination of industrial and agricultural pollutants such as heavy metal ions, hydrocarbons, and pesticides at very low concentration levels is one of the main goals for environmental science nowadays [3].

Conventional analytical techniques such as gas chromatography, inductively coupled plasma mass spectroscopy (ICP- 
MS), and high-performance liquid chromatography (HPLC) are very sensitive and reliable [4]. However, they suffer from the disadvantages of high cost, time consuming, the need for highly trained technicians, and the fact that they are mostly laboratory bound.

An alternative approach lies in the use of biosensors which present distinct advantages of high specificity, fast response times, portability, ease of use, and low cost $[5,6]$. Since the invention of the electrochemical biosensor for glucose detection in 1962, biosensors have been intensively studied and extensively utilized in various applications, ranging from public health and environmental monitoring to homeland security and food safety [7]. Electrochemical methods can be successfully used for simple and rapid detection of the abovementioned pollutants in the aquatic environment [8].

There are two approaches of using biosensors for environmental control: (i) immuno-sensing where pollutants can be bound to highly specific receptors, i.e., antibodies or aptamers, and (ii) inhibition sensors mostly based on enzymes which are inhibited by pollutants [9]. The immuno-sensors, despite their high selectivity and sensitivity of detection, require the production (or synthesis) of a large number of bio-receptors for every pollutant which may come at a cost. The inhibition sensor approach of using a small number of bio-receptors is much simpler and less expensive although it may not be highly sensitive and not particularly selective because the receptors could be affected by different types of pollutants. Therefore, in order to identify the pollutants, several sensors having different bio-receptors have to be used simultaneously which brings the concept of a sensor array and the associated data processing, for example, artificial neural network (ANN) [10].

Instead of extremely fragile and sensitive-toenvironment enzymes, whole cells and bacteria can be used as much more robust bio-receptors in inhibition sensors and sensor arrays. Several successful inhibition sensor array developments utilizing whole cells $[11,12]$ and bacteria [13] were reported recently. Our recent research proved the concept of pattern recognition of water pollutants using optical and electrochemical measurements of both liquid bacterial samples and immobilized bacteria [14-16] and a limited number of pollutants of different types, e.g., heavy metals, pesticides, and petro-chemicals, in rather high concentrations.

In this work, we continue the development of a bacteriabased electrochemical sensor array for detection of a wide range of pollutants including several heavy metals, pesticides, and petrochemicals in low concentrations down to $0.1 \mu \mathrm{M}$. The analysis of a large number of data, e.g., the sensor responses of each channel to every pollutant, is carried out using the MatLab ANN programme.

\section{Experimental methodology}

\section{Preparation of bacterial samples}

Three types of bacteria were selected for this work: (i) Escherichia coli (E. coli, K12 strain), a gram-negative bacterial type generally sensitive to different types of pollutants including heavy metals, pesticides, and hydrocarbons [17]; (ii) Shewanella oneidensis (S. oneidensis MR-1 strain), gram-negative bacteria known to be tolerant of heavy metals [18]; and (iii) methanotrophic bacteria (Methylococcus capsulatus Bath strain), gram-negative bacteria which consume some petrochemicals as nutrients $[19,20]$. LuriaBertani (LB) broth was used as a growth medium for both E. coli and S. oneidensis bacterial cell cultures [21], while M. capsulatus (Bath) were grown in nitrate mineral salts (NMS) medium [22]. The bacterial growth media and phosphate buffer saline (PBS) were acquired from Sigma-Aldrich Co. Other chemicals, i.e., $\mathrm{HgCl}_{2}, \mathrm{PbCl}_{2}$, and $\mathrm{CdCl}_{2}$ salts; atrazine, simazine, and DDVP; hexane, octane, pentane, toluene, pyrene, and ethanol; and poly L-lysine (PLl), were also purchased from Sigma-Aldrich Co.

\section{Bacterial culture growth}

All bacterial strains used in this study were provided by the Biomolecular Research Centre, Sheffield Hallam University. All strains were stored at $-70{ }^{\circ} \mathrm{C}$ in $15 \%$ glycerol to be used as a bacterial source in future. Cultivation of bacteria was carried out in several stages. The first step was to cultivate a specific strain of bacteria in a Petri dish containing solid agar. In the second stage, one colony of bacteria was added into a sterile flask containing $50 \mathrm{ml}$ of liquid LB broth (for E. coli and $S$. oneidensis) or NMS medium (for M. capsulatus). Finally, the flask containing the bacterial culture was placed inside the incubator operating at $150 \mathrm{rpm}$ shaking speed. The incubation temperature was $30{ }^{\circ} \mathrm{C}$ for Shewanella oneidensis and M. capsulatus (Bath), while $37^{\circ} \mathrm{C}$ was used for E. coli. Bacterial growth time was $16 \mathrm{~h}$ for E. coli, $24 \mathrm{~h}$ for Shewanella oneidensis, and $72 \mathrm{~h}$ for M. capsulatus (Bath).

\section{Bacterial sensor array construction}

A bacterial biosensor array (or multi-sensor) consisted of three screen-printed electrodes having different sensing characteristics towards investigated analytes. The sensor array was fabricated by immobilizing the three types of bacterial cells, on the surface of screen-printed gold electrodes via poly L-lysine (PLl) [23] (see Fig. 1). In order to achieve the highest surface coverage, the maximal concentration of bacterial cells from 10 to $3010^{9} \mathrm{~cm}^{-3}$ corresponding to the end of the bacterial exponential growth phase, e.g., $16 \mathrm{~h}$ for $E$. coli, $24 \mathrm{~h}$ for $S$. oneidensis, and $72 \mathrm{~h}$ for M. capsulatus, was used for 


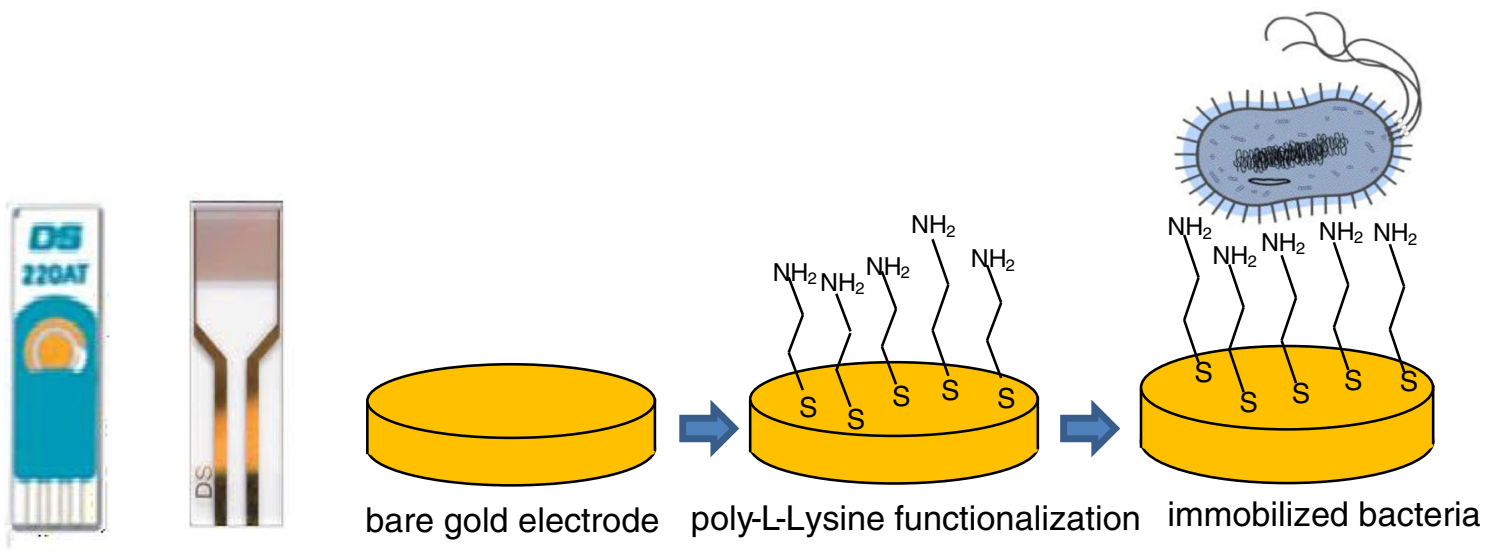

(a)

(b)

(c)

Fig. 1 DropSens three-electrode assembly (a), DropSens interdigitated electrodes (b), schematic diagram of the bacterial immobilization procedure (c)

immobilization. For this reason, the surface of gold was treated in a 1:1000 mixture of PLl $(0.1 \mathrm{mg} / \mathrm{ml})$ and deionized water for $1 \mathrm{~h}$ at $37^{\circ} \mathrm{C}$. Then, bacteria were immobilized by dropping stock solutions of E. coli, or M. capsulatus (Bath), or $S$. oneidensis on the modified electrodes, incubating for $1 \mathrm{~h}$, and then washing out non-bound bacteria with PBS [15].

\section{Preparation of analyte solutions}

The inhibition effects on the abovementioned bacteria have been studied by exposing them to the following chemicals (pollutants): $\mathrm{HgCl}_{2}, \mathrm{PbCl}_{2}$, and $\mathrm{ZnCl}_{2}$ salts; atrazine, simazine, and DDVP; and hexane, pentane, octane, toluene, ethanol, and pyrene. Their solutions of different concentrations $(0.1,1,10$, 100 , and $1000 \mu \mathrm{M}$ ) were prepared by multiple dilution of $1 \mathrm{mM}$ stock solution of each analyte dissolved in deionized water. Forty percent ethanol solution in water was used for dissolving the hydrocarbons, toluene, and pyrene. The samples of immobilized bacteria were treated by immersing them in the required solutions of the above chemicals for $2 \mathrm{~h}$.

\section{Electrochemical experimental measurements}

All cyclic voltammogram (CV) electrochemical measurements were carried out on a DropSTAT4000P potentiostat instrument (from DropSens) controlled by Autolab software using DropSens screen-printed gold electrodes (SPGEs); the voltage range from -0.5 to $+0.5 \mathrm{~V}$ and the scan rate of $10 \mathrm{mV} / \mathrm{s}$ were used. SPGEs have a conventional threeelectrode configuration with gold working and counter electrodes and $\mathrm{Ag} / \mathrm{AgCl}$ pseudo-reference electrode (see Fig. 1a) [24]. The CV measurements were carried on SPGEs with all three types of bacteria immobilized on the surface of gold electrodes via poly L-lysine (PLl). The $\mathrm{CV}$ measurements were carried out in PBS both before and after treatment with $\left(\mathrm{Hg}^{2+}\right),\left(\mathrm{Pb}^{2+}\right)$, and $\left(\mathrm{Cd}^{2+}\right)$ salts, pesticides (atrazine, simazine, and DDVP), and hydrocarbons (hexane, pentane, octane, toluene, pyrene, and ethanol) in different concentrations.

Impedance spectra were measured using an impedance analyzer (4000A EG \& G Instrument) and gold interdigitated electrodes (from DropSens) containing 250 fringes on each side spaced by $5 \mu \mathrm{m}$, the overlapping length $6.76 \mathrm{~mm}$ (see Fig. 1b). The AC voltage amplitude was $5 \mathrm{mV}$ with the frequency varied from $100 \mathrm{mHz}$ to $100 \mathrm{kHz}$; no DC bias was applied [25]. The use of interdigitated electrodes was recommended by the supplier (DropSens) for impedance measurements. Similarly to CVs, the impedance spectra measurements were carried out on electrodes coated with immobilized bacteria, in buffer solutions containing different pollutant concentrations.

\section{Electrochemical measurement results}

\section{Cyclic voltammograms}

Typical cyclic voltammograms (CVs) in Fig. 2a-c show the increase in both anodic and cathodic currents upon increasing the concentration of pollutants in all three cases presented: the toluene which effects the immobilized E.coli (a), simazine effect on $M$. capsulatus (b), and $\mathrm{HgCl}_{2}$ effect on $S$. oneidensis (c). Similar results were observed for the effect of all other pollutants used for the respective bacteria.

It should be noted that CVs of uncoated electrodes in Fig. 2 show the characteristic anodic peaks (at about +0.3 to $+0.4 \mathrm{~V}$ ) and cathodic peaks (at about $-0.15 \mathrm{~V}$ ) which are associated with electrochemical reactions in PBS. The bacteria immobilized on the electrode surface act as an insulating layer, thus reducing the current substantially. The observed threefold drop of the DC current after coating the electrodes with bacteria corresponds approximately to $30 \%$ bacterial surface coverage. However, the bacteria are damaged by exposure to pollutants and their insulating properties are reduced. This clearly explains the observed behavior. The correlations 

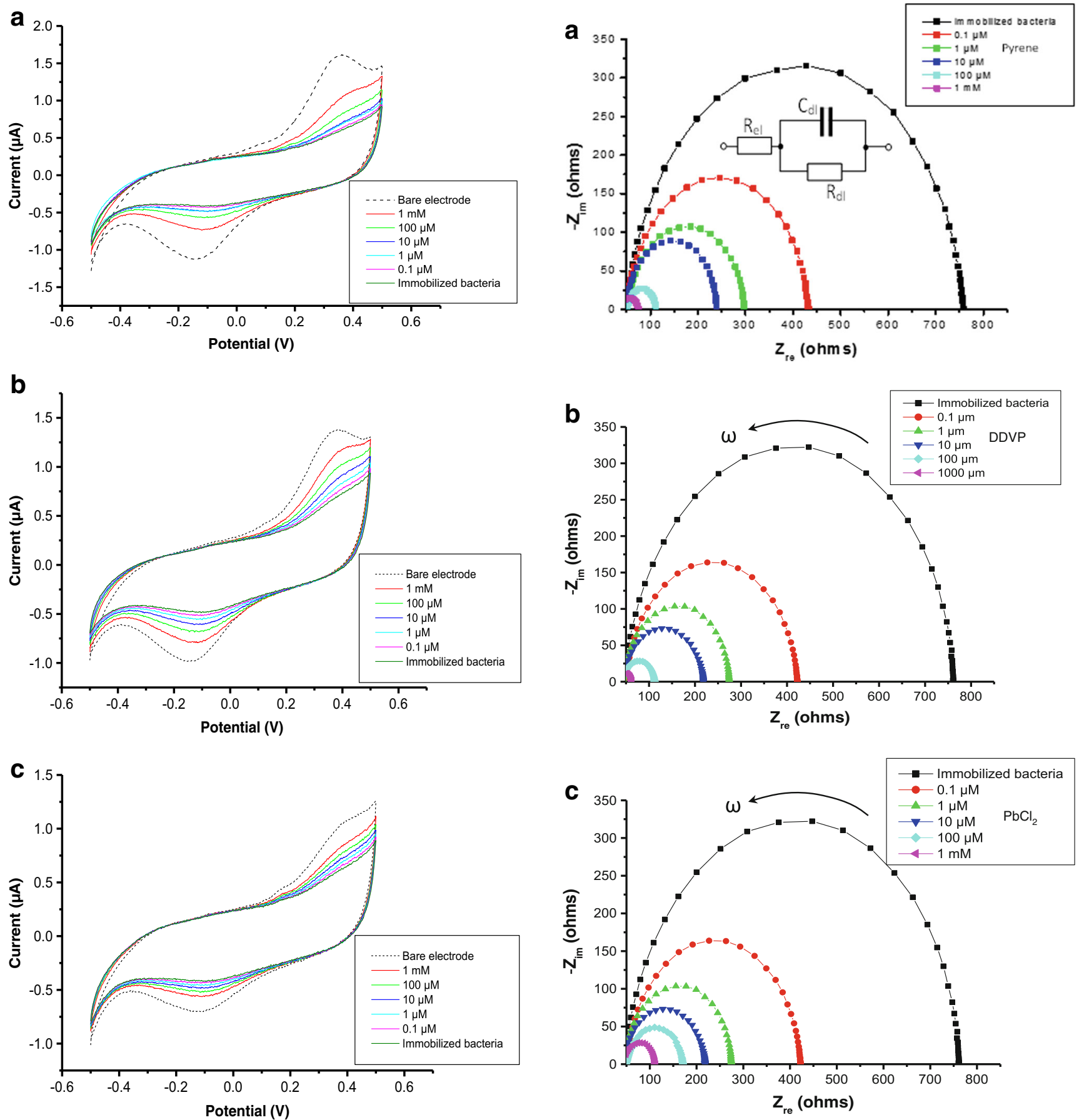

Fig. 2 CVs recorded on electrodes with immobilized $E$. coli treated with toluene (a), M. capsulatus treated with atrazine (b), and S. oneidensis treated with $\mathrm{HgCl}_{2}$ (c) in different concentrations

between the values of the anodic current and pollutant concentrations were therefore established which constitutes the main principle of electrochemical detection of pollutants using bacteria.

\section{Electrochemical impedance spectroscopy}

The electrical properties of bacteria immobilized on metal electrodes were studied with electrochemical impedance

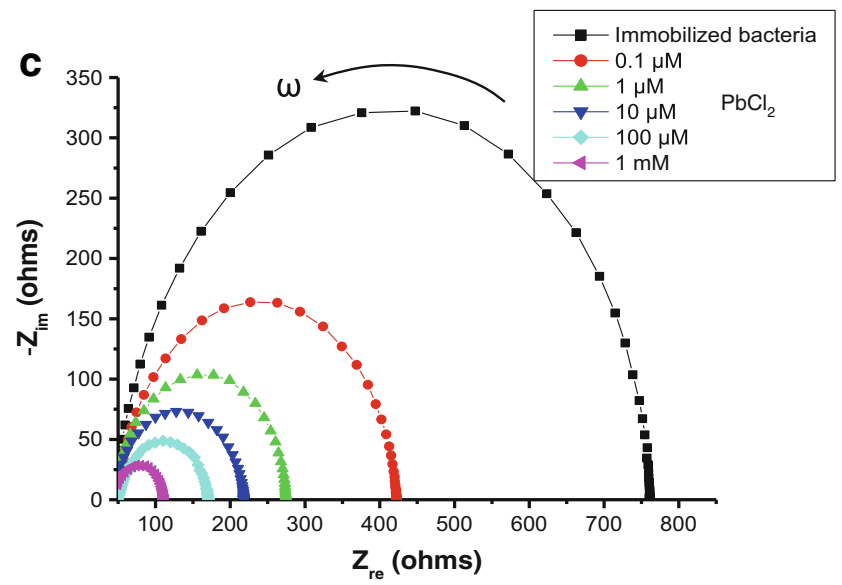

Fig. 3 Examples of Nyquist plots $\left(-Z_{\mathrm{im}}\right.$ vs $Z_{\mathrm{re}}$ ) for interdigitated electrodes with immobilized bacteria exposed to different pollutants of different concentrations: $E$. coli treated with pyrene (a), M. capsulatus treated with DDVP (b), and $S$. oneidensis treated with $\mathrm{PbCl}_{2}$ (c); the equivalent circuit is shown as an inset in $\mathbf{a}$; the arrows indicate the direction of frequency increase

spectroscopy. Typical results of this study are presented as Nyquist plots in Fig. 3. As one can see, for all three graphs selected which correspond to three bacteria, the exposure to pollutants caused both the reduction in size of semi-circles and their shift to low resistance values which is an indication of the decrease in the double-layer resistance. 
More detailed analysis of the impedance spectra could be done using a simplified equivalent circuit diagram (shown as an inset in Fig. 3a) which consists of a connected-in-parallel resistor $R_{d b}$ and capacitor $C_{d b}$ of an electrical double layer on the electrode surface and the resistor of the electrolyte $R_{e l}$ connected in series. The negative sign of the imaginary part of the impedance indicated its capacitive character.

According to the theory [26], at high frequencies $(\omega \rightarrow \infty)$, the real part of impedance $Z_{r e}=R_{e l}$, while at low frequencies $(\omega \rightarrow 0), Z_{r e}=R_{e l}+R_{d b} \approx R_{d b}$ because $R_{e l}$ is usually quite small $R_{e l}<<R_{d b}$. The reduction on the values of $R_{d b}$ as a result of bacterial exposure to pollutants is apparent from the impedance spectroscopy data presented in Fig. 3. This confirms the previously observed facts that bacteria are losing their insulating properties upon exposure to pollutants.

More detailed analysis of the effect of pollutants was carried out by presenting the data of $\mathrm{CV}$ measurements as the dependence of the anodic current at $+0.5 \mathrm{~V}$ against the pollutant concentration; such dependences are shown in Fig. 4. The comparison of the effect of different pollutants on the three types of bacteria used has to be performed using the relative changes of anodic current $\left(\Delta I_{\mathrm{A}}\right)$ normalized by the reference current $I_{\mathrm{A} 0}$ corresponding to the CVs recorded on electrodes with immobilized bacteria in PBS without addition of pollutants:

$\Delta I_{\mathrm{A}} / I_{\mathrm{A} 0}=\left(I_{\mathrm{A}}-I_{\mathrm{A} 0}\right) / I_{\mathrm{A} 0}$

As was concluded from the impedance spectra data, the effect of the pollutants (even metal salts) on the total resistance (and thus the current) is negligibly small.

As one can see from Fig. $4 \mathrm{a}$, the effects of $\mathrm{CdCl}_{2}$ on $S$. oneidensis, $M$. capsulatus, and E. coli are completely different: $\Delta I_{\mathrm{A}} / I_{\mathrm{A} 0}$ goes up with the increase in $\mathrm{CdCl}_{2}$ concentration for E. coli and M. capsulatus which means that both E. coli and M. capsulatus bacteria are inhibited by $\mathrm{Cd}^{2+}$ ions and becoming less electrically resisting, while $\Delta I_{\mathrm{A}} / I_{\mathrm{A} 0}$ is almost flat at low concentrations of $\mathrm{CdCl}_{2}$ and slightly increases at a high concentration of $1 \mathrm{mM}$. This means that $S$. oneidensis are practically not affected by $\mathrm{CdCl}_{2}$ in low concentrations but inhibited at high concentrations. Similarly, in Fig. 4b, atrazine inhibits E. coli and M. capsulatus, while its effect on $S$. oneidensis is more or less independent on atrazine concentration (excluding the high concentration of $1 \mathrm{mM}$ ). According to data in Fig. 4c, octane inhibits E. coli and $S$. oneidensis, but has a much smaller inhibition effect on M. capsulatus. The above results are very promising and demonstrate a possibility of pattern recognition of pollutants using a bacterial sensor array.

The reproducibility of CV and EIS measurements is reasonably good, e.g., within $10 \%$ of current and impedance values. Stability of the samples with immobilized bacteria was studied, and it was found that the storage of samples with
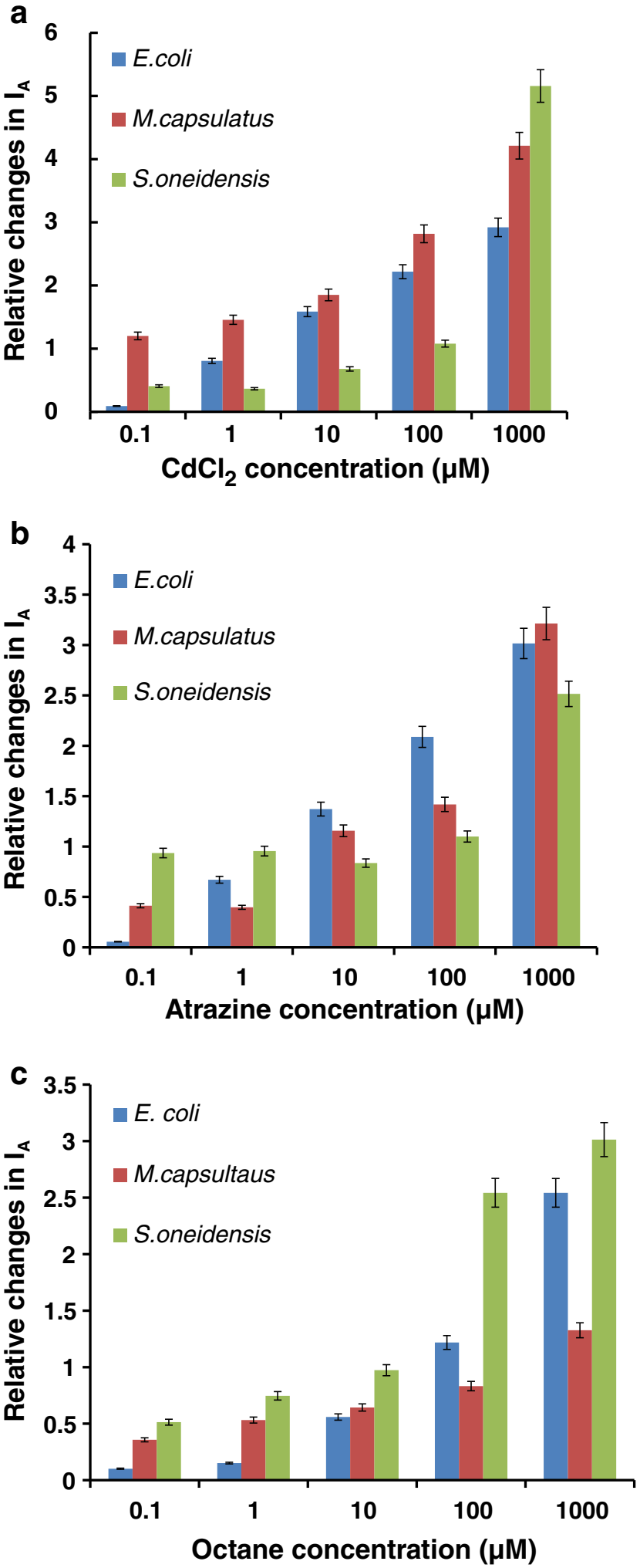

Fig. 4 The dependence of relative changes of the anode at $+0.5 \mathrm{~V}$ for immobilized E. coli, M. capsulatus, and S. oneidensis on the concentration of $\mathrm{CdCl}_{2}(\mathbf{a})$, atrazine (b), and octane (c)

immobilized bacteria for $24 \mathrm{~h}$ in the fridge at $4{ }^{\circ} \mathrm{C}$ has no effect on sensor responses. The activity of bacteria is, 
Fig. 5 3D graphs of responses of three sensing channels (having different bacteria) to different pollutants: toluene, simazine, and $\mathrm{HgCl}_{2}$ (a); pyrene, DDVP, and $\mathrm{PbCl}_{2}$ (b); and octane, atrazine, and $\mathrm{CdCl}_{2}(\mathbf{c})$ in different concentrations from 0.1 to $100 \mu \mathrm{M}$. Arrows indicate the directions of concentration increase
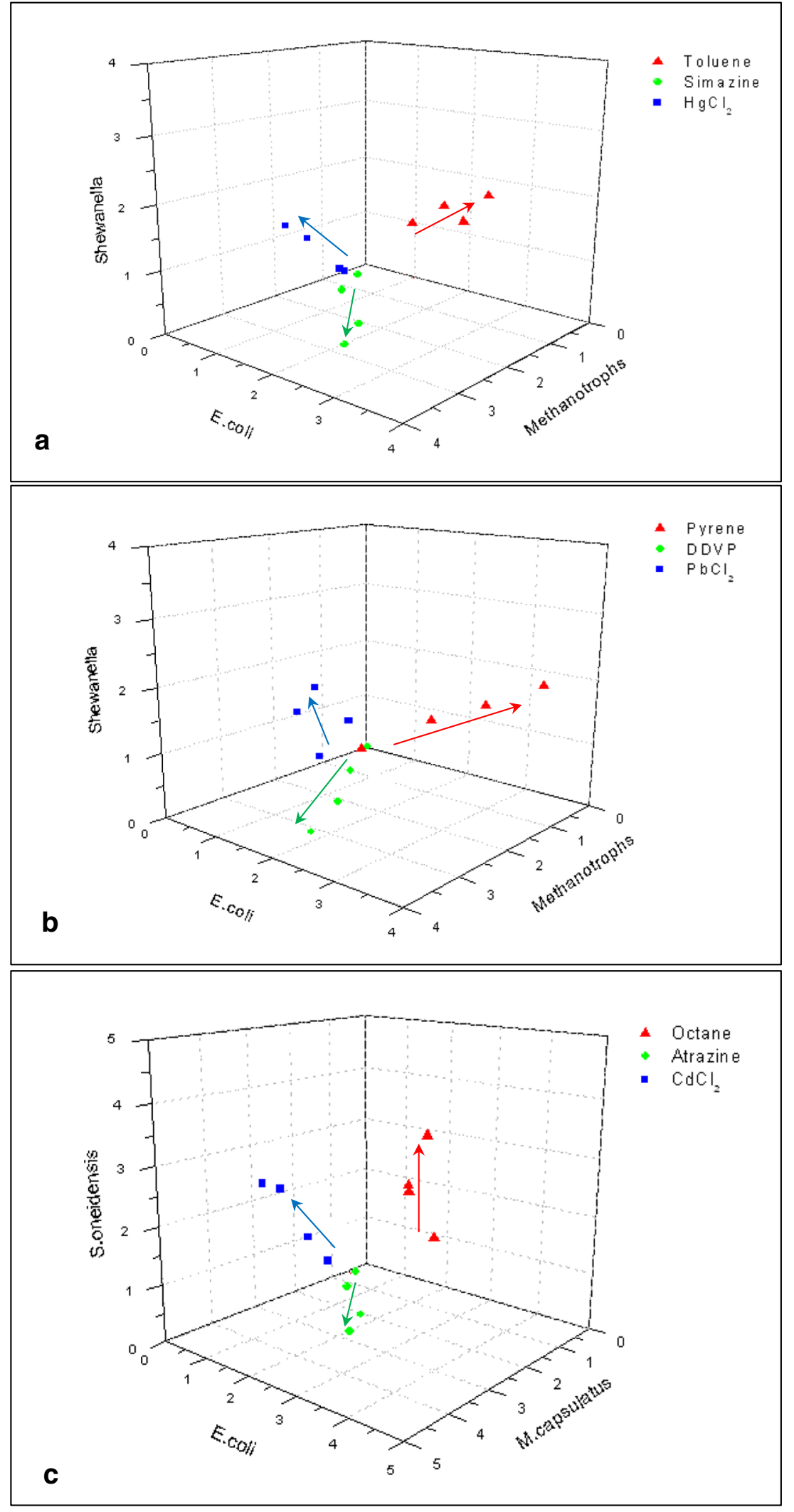
Fig. 6 ANN architecture for classification of pollutants and estimation of their concentration

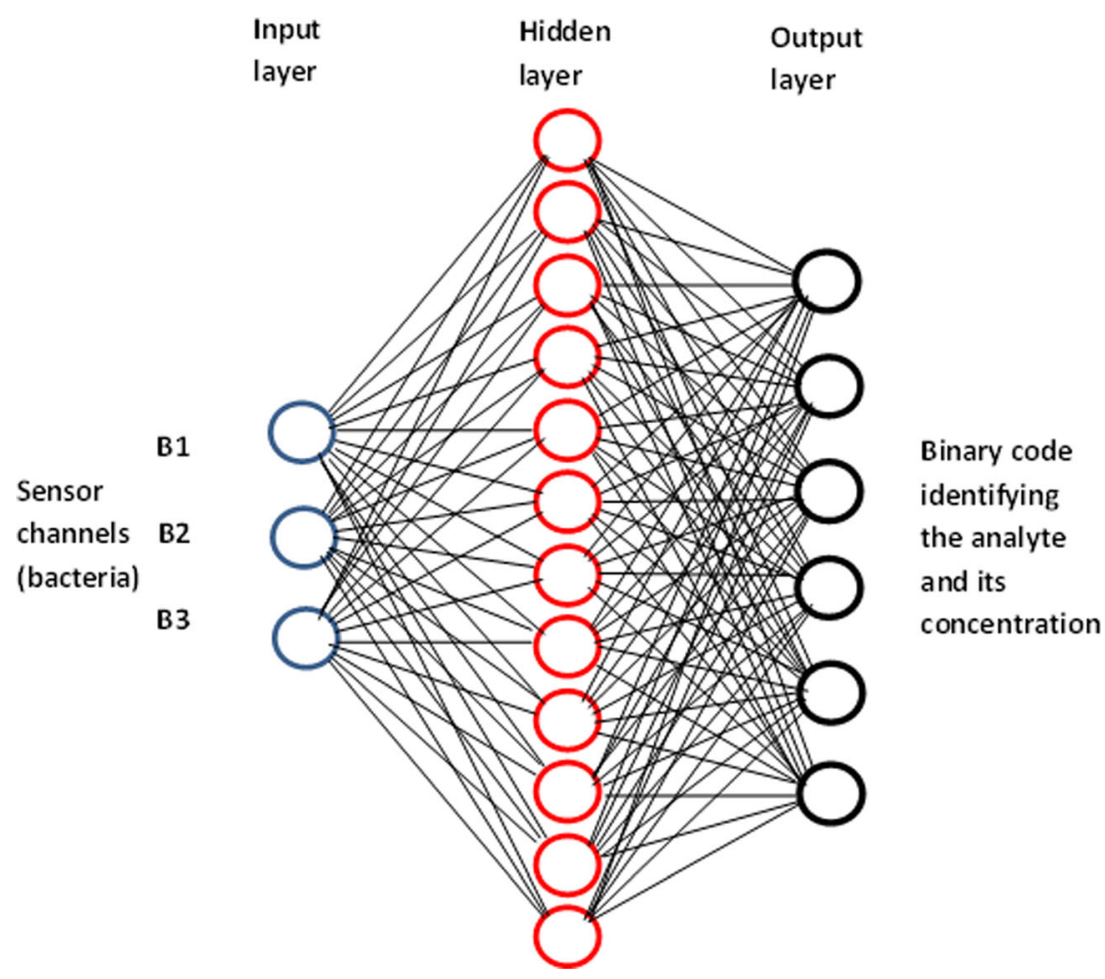

pesticides (green dots which appear at the bottom part), and petrochemicals (red dots which appear on the right side). It can be concluded that a simple pseudo-3D graph of the three sensor responses allows the classification of pollutants studied into three groups, e.g., heavy metals, pesticides, and petrochemicals, which demonstrate clearly the principles of pattern recognition. Further identification of pollutants within each group, for example, distinguishing between $\mathrm{Hg}, \mathrm{Pb}$, and $\mathrm{Cd}$ ions, is difficult to achieve using such a simple approach because all the data points for heavy metals appeared in the same section of 3D space in Fig. 5. Precise identification of pesticides and petrochemicals faces the same difficulties. It is also difficult to estimate the concentration of pollutants because of random scattering of data points.

\section{ANN data analysis of water pollutants}

Much more accurate recognition of pollutants was achieved with the use of the artificial neural network (ANN) programme written using Neural Network Toolbox, version 4.0, within MATLAB 6.1 (Mathworks, Natick, MA). The ANN model, shown in Fig. 6, consists of three layers: (i) the input layer of the responses of three sensing channels (containing different bacteria); (ii) the hidden layer containing 12 neurons corresponding to 12 pollutants studied; and (iii) the output layer representing a six-digit binary code which identifies the type of pollutants and their concentration.

The designed ANN programme is therefore capable of identification of pollutants as well as the rough estimation of their concentration by rounding the output to the nearest metal ions (blue dots which appear on the left side of the graphs), 
Table 1 The results of ANN identification of pollutants and estimation of their concentration

\begin{tabular}{|c|c|c|c|c|c|c|c|c|c|c|c|}
\hline \multicolumn{3}{|c|}{ Input values } & \multicolumn{9}{|c|}{ Output values } \\
\hline \multirow[t]{2}{*}{ E. coli } & \multirow[t]{2}{*}{ M. capsulatus } & \multirow[t]{2}{*}{ S. oneidensis } & \multicolumn{6}{|c|}{ Binary code } & \multirow[t]{2}{*}{ Pollutant } & \multicolumn{2}{|c|}{ Concentration $(\mu \mathrm{M})$} \\
\hline & & & & & & & & & & Obtained & Actual \\
\hline 0.09417 & 0.58032 & 0.06211 & 0 & 0 & 0 & 0 & 1 & 0 & $\mathrm{Hg}^{2+}$ & 1 & 0.66 \\
\hline 0.46138 & 1.48214 & 1.08641 & 0 & 0 & 0 & 0 & 1 & 1 & & 10 & 1.3 \\
\hline 1.19823 & 1.37532 & 1.65302 & 0 & 0 & 0 & 1 & 0 & 0 & & 100 & 66 \\
\hline 0.09023 & 0.45121 & 0.67656 & 0 & 0 & 0 & 1 & 1 & 1 & $\mathrm{~Pb}^{2+}$ & 1 & 1.25 \\
\hline 0.48352 & 1.56176 & 0.87403 & 0 & 0 & 1 & 0 & 0 & 0 & & 10 & 22 \\
\hline 1.21501 & 1.71608 & 2.47263 & 0 & 0 & 1 & 0 & 0 & 1 & & 100 & 83 \\
\hline 0.54321 & 0.59745 & 1.31435 & 0 & 0 & 1 & 1 & 0 & 0 & $\mathrm{Cd}^{2+}$ & 1 & 1.37 \\
\hline 0.76232 & 1.13421 & 1.54623 & 0 & 0 & 1 & 1 & 0 & 1 & & 10 & 26 \\
\hline 1.55412 & 1.66534 & 1.82152 & 0 & 0 & 1 & 1 & 1 & 0 & & 100 & 76 \\
\hline 0.55657 & 1.01232 & 0.01566 & 0 & 1 & 0 & 0 & 0 & 1 & Atrazine & 1 & 1.45 \\
\hline 0.30508 & 2.09684 & 0.08508 & 0 & 1 & 0 & 0 & 1 & 0 & & 10 & 24 \\
\hline 1.06593 & 2.95676 & 0.97593 & 0 & 1 & 0 & 0 & 1 & 1 & & 100 & 71 \\
\hline 0.76231 & 1.20342 & 0.18784 & 0 & 1 & 0 & 1 & 1 & 0 & Simazine & 1 & 1.61 \\
\hline 1.54231 & 2.47652 & 0.36941 & 0 & 1 & 0 & 1 & 1 & 1 & & 10 & 12.5 \\
\hline 2.14325 & 2.89732 & 0.89876 & 0 & 1 & 1 & 0 & 0 & 0 & & 100 & 87 \\
\hline 0.50453 & 1.13423 & 0.05566 & 0 & 1 & 1 & 0 & 1 & 1 & DDVP & 1 & 1.1 \\
\hline 1.65483 & 2.08563 & 0.02508 & 0 & 1 & 1 & 1 & 0 & 0 & & 10 & 13.8 \\
\hline 2.26314 & 2.87342 & 0.09593 & 0 & 1 & 1 & 1 & 0 & 1 & & 100 & 99 \\
\hline 0.03290 & 1.24231 & 0.49265 & 1 & 0 & 0 & 0 & 0 & 0 & Hexane & 1 & 1.2 \\
\hline 1.04398 & 2.72134 & 0.56021 & 1 & 0 & 0 & 0 & 0 & 1 & & 10 & 32 \\
\hline 2.89296 & 2.36532 & 0.75134 & 1 & 0 & 0 & 0 & 1 & 0 & & 100 & 83 \\
\hline 0.02965 & 1.299123 & 0.27365 & 1 & 0 & 0 & 1 & 0 & 1 & Octane & 1 & 1.22 \\
\hline 0.95120 & 2.61860 & 0.41931 & 1 & 0 & 0 & 1 & 1 & 0 & & 10 & 17 \\
\hline 2.00623 & 2.92861 & 0.65108 & 1 & 0 & 0 & 1 & 1 & 1 & & 100 & 77 \\
\hline 0.71525 & 1.47123 & 0.51132 & 1 & 0 & 1 & 0 & 1 & 0 & Pentane & 1 & 1.6 \\
\hline 1.29723 & 2.68243 & 0.74167 & 1 & 0 & 1 & 0 & 1 & 1 & & 10 & 18 \\
\hline 2.26211 & 2.85412 & 0.97133 & 1 & 0 & 1 & 1 & 1 & 0 & & 100 & 89 \\
\hline 0.90123 & 2.51252 & 0.46326 & 1 & 0 & 1 & 1 & 1 & 1 & Toluene & 1 & 1.2 \\
\hline 2.03251 & 2.85421 & 0.59131 & 1 & 1 & 0 & 0 & 0 & 0 & & 10 & 11 \\
\hline 1.98589 & 2.85862 & 2.87109 & 1 & 1 & 0 & 0 & 0 & 1 & & 100 & 93 \\
\hline 0.80173 & 1.01099 & 0.38134 & 1 & 1 & 0 & 1 & 0 & 0 & Pyrene & 1 & 1.4 \\
\hline 2.01351 & 1.13209 & 0.53965 & 1 & 1 & 0 & 1 & 0 & 1 & & 10 & 11.6 \\
\hline 2.90598 & 1.07213 & 1.43312 & 1 & 1 & 0 & 1 & 1 & 0 & & 100 & 83 \\
\hline 0.15432 & 0.51974 & 0.63144 & 1 & 1 & 1 & 0 & 0 & 1 & Ethanol & 1 & 1.5 \\
\hline 0.48453 & 1.53342 & 0.54762 & 1 & 1 & 1 & 0 & 1 & 0 & & 10 & 12.1 \\
\hline 1.31541 & 1.81653 & 2.65021 & 1 & 1 & 1 & 0 & 1 & 1 & & 100 & 97 \\
\hline
\end{tabular}

quantized concentration value, e.g., $0.1 \mu \mathrm{M}, 1 \mu \mathrm{M}, 10 \mu \mathrm{M}$, $100 \mu \mathrm{M}$, and $1 \mathrm{mM}$.

The ANN was trained by multiple feeding the experimental results, e.g., the responses of all three sensing channels to all 12 pollutants $\left(\mathrm{Hg}^{2+}, \mathrm{Pb}^{2+}, \mathrm{Cd}^{2+}\right.$, atrazine, simazine, DDVP, hexane, pentane, pyrene, toluene, octane, and ethanol) in five concentrations $(0.1 \mu \mathrm{M}, 1 \mu \mathrm{M}, 10 \mu \mathrm{M}, 100 \mu \mathrm{M}$, and $1 \mathrm{mM})$. The training data are presented in Table S1 in the Electronic
Supplementary Material (ESM). This table also contains the identification digital codes. The ANN training procedure exploited the Levenberg-Marquardt algorithm to optimize the weights of neurons in a hidden layer. This algorithm appeared to be the fastest method for the network training using the limited experimental data of this study. A hyperbolic tangent was used as the activation function for the hidden neurons, and a log-sigmoid function was used for the output 
neurons. The training was performed for 250,000 epochs (e.g., 250,000 repetitions of data feeding) with the mean square error (MSE) goal set to $10^{-10}$. Figure $\mathrm{S} 1$ in ESM shows the saturation of MSE at about 250,000 epochs.

After the training, the ANN programme was tested by feeding the data obtained from the bacterial sensor array for PBS solutions spiked with a particular concentration of pollutants randomly selected within the $1-100-\mu \mathrm{M}$ concentration range. The results of such tests are summarized in Table 1. The ANN outcome is a six-digit code representing the type of pollutant and its concentration rounded to the nearest quantized concentration value.

Despite the limited amount of data for ANN training, the programme managed to identify the pollutants correctly. The comparison of values in the last two columns representing, respectively, the obtained and actual concentrations of pollutants showed that the concentration was estimated correctly. For example, the sample spiked with $1.45 \mu \mathrm{M}$ of atrazine was identified by binary code 010001 which corresponds to atrazine in a concentration of $1 \mu \mathrm{M}$; the sample spiked with $0.66 \mu \mathrm{M}$ of $\mathrm{HgCl}_{2}$ was identified by code 000001 corresponding to $\mathrm{Hg}^{2+}$ in a concentration of $1 \mu \mathrm{M}$; the sample spiked with $83 \mu \mathrm{M}$ of pyrene was identified by code 110110 as pyrene in a concentration of $100 \mu \mathrm{M}$.

The results obtained are very promising since simple electrochemical measurements of the anodic current at $+0.5 \mathrm{~V}$ combined with ANN-based data processing allow both the identification of the pollutants studied and a rough estimation of their concentrations.

\section{Conclusions and future work}

A series of electrochemical measurements, e.g., cyclic voltammograms and impedance spectra, on screen-printed electrodes with immobilized bacteria proved the concept of using bacteria as bioreceptors in the inhibition sensor array. All three bacteria studied, E. coli, M. capsulatus, and S. oneidensis, immobilized on the electrodes appeared to act as insulators and reduced the charge transfer. The inhibition effect of 12 pollutants studied lies in the reduction of bacterial electrical resistivity. The inhibition effect depends on the type of bacteria, the type of pollutant, and their concentration which provides an opportunity for pattern recognition of pollutants using simple and illustrative pseudo-3D plots of sensor responses. The use of ANN software for data processing allowed the more accurate identification of water pollutants, e.g., heavy metals, pesticides, and hydrocarbons as well as the estimation of their concentration in the range from $0.1 \mu \mathrm{M}$ to $1 \mathrm{mM}$.

The developed electrochemical inhibition sensor array based on bacteria immobilized on the surface of screenprinted electrodes proved to be a useful analytical tool for water pollution analysis. Such a biosensor array may fit the purpose of preliminary testing (or screening) of water samples. The samples identified by the sensor array as "contaminated" by a particular pollutant in a certain concentration range can be passed to specialized laboratories for further more detailed and more accurate testing. In this way, both the time and cost of analysis of water samples could be substantially reduced.

Future work which is currently underway focuses on extending the range of pollutants, the improvement of the ANN data processing, and the testing of real water samples. The ANN software should be able to identify pollutants in complex samples (including real samples of water from different sources) containing a mixture of pollutants. The evaluation of pollutant concentration should be also more precise; for that purpose, a separate ANN programme employing a polynomial approximation of concentration dependencies of sensor responses has to be designed.

Acknowledgments One of the authors would like to thank the Iraqi Government, Ministry of Higher Education and Scientific Research, and the University of Basrah for sponsoring the $\mathrm{PhD}$ project.

\section{Compliance with ethical standards}

The presented research did not involve human participants and/or animals.

Conflict of interest The authors declare that they have no conflict of interest.

Open Access This article is distributed under the terms of the Creative Commons Attribution 4.0 International License (http:// creativecommons.org/licenses/by/4.0/), which permits unrestricted use, distribution, and reproduction in any medium, provided you give appropriate credit to the original author(s) and the source, provide a link to the Creative Commons license, and indicate if changes were made.

\section{References}

1. Environment Agency. Groundwater risk assessment for your environmental permit. https://www.gov.uk/guidance/groundwaterriskassessment-for-your-environmental-permit\#develop-yourconceptual-model, 2017.

2. Scognamiglio V, Pezzotti G, Pezzotti I, Cano J, Buonasera K, Giannini D, et al. Biosensors for effective environmental and agrifood protection and commercialization: from research to market. Microchim Acta. 2010;170(3-4):215-25.

3. Manahan S. Environmental chemistry: CRC press; 2017.

4. Namieśnik J. Trends in environmental analytics and monitoring. Crit Rev Anal Chem. 2000;30(2-3):221-69.

5. Honeychurch K, Piano M. Electrochemical (bio) sensors for environmental and food analyses. Biosensors. 2018;8:57.

6. Hernandez-Vargas G, Sosa-Hernández JE, Saldarriaga-Hernandez S, Villalba-Rodríguez AM, Parra-Saldivar R, Iqbal H. Electrochemical biosensors. A solution to pollution detection with reference to environmental contaminants. Biosensors. 2018;8:29.

7. Su L, Jia W, Hou C, Lei Y. Microbial biosensors: a review. Biosens Bioelectron. 2011;26(5):1788-99. 
8. Rodriguez-Mozaz S, de Alda MJL, Barcelo D. Biosensors as useful tools for environmental analysis and monitoring. Anal Bioanal Chem. 2006;386(4):1025-41.

9. Nabok A, Haron S, Ray AK. Optical enzyme sensors based upon silicon planar waveguide coated with composite polyelectrolyte film. Appl Surf Sci. 2004;238:423-8.

10. Gutés A, Céspedes F, Alegret S, Del Valle M. Determination of phenolic compounds by a polyphenol oxidase amperometric biosensor and artificial neural network analysis. Biosens Bioelectron. 2005;20(8):1668-73.

11. Eltzov E, Marks RS. Whole-cell aquatic biosensors. Anal Bioanal Chem. 2011;400(4):895-913.

12. Yagi K. Applications of whole-cell bacterial sensors in biotechnology and environmental science. Appl Microbiol Biotechnol. 2007;73(6):1251-8.

13. Lee JH, Mitchell RJ, Kim BC, Cullen DC, Gu MB. A cell array biosensor for environmental toxicity analysis. Biosens Bioelectron. 2005;21(3):500-7.

14. Abu-Ali H, Nabok A, Smith T, Al-Shanawa M. Inhibition biosensor based on DC and AC electrical measurements of bacteria samples. Procedia Technol. 2017;27:129-30.

15. Abu-Ali H, Nabok A, Smith T, Al-Shanawa M. Development of electrochemical inhibition biosensor based on bacteria for detection of environmental pollutants. Sens Bio-Sensing Res. 2017;13: 109-14.

16. Abu-Ali H, Nabok A, Smith T, Al-Shanawa M. Electrochemical inhibition biosensor array for rapid detection of water pollution based on bacteria immobilized on screen-printed gold electrodes. Eur Chem Bull. 2019;7(10):9-11.

17. Ramos JL, Duque E, Gallegos MT, Godoy P, Ramos-Gonzalez MI, Rojas A, et al. Mechanisms of solvent tolerance in gram-negative bacteria. Ann Rev Microbiol. 2002;56(1):743-68.
18. Suresh AK, Pelletier DA, Wang W, Moon JW, Gu B, Mortensen NP, et al. Silver nanocrystallites: biofabrication using Shewanella oneidensis, and an evaluation of their comparative toxicity on gramnegative and gram-positive bacteria. Environ Sci Technol. 2010;44(13):5210-5.

19. Smith TJ, Dalton H. Biocatalysis by methane monooxygenase and its implications for the petroleum industry. Pet Biotechnol Dev Perspect. 2004:177-92.

20. Han JI, Lontoh S, Semrau JD. Degradation of chlorinated and brominated hydrocarbons by Methylomicrobium album BG8. Arch Microbiol. 1999;172(6):393-400.

21. Sezonov G, Joseleau-Petit D, D'Ari R. Escherichia coli physiology in Luria-Bertani broth. J Bacteriol. 2007;189(23):8746-9.

22. Smith TJ, Murrell JC. Mutagenesis of soluble methane monooxygenase. Methods Enzymol. 2011;495:135-47.

23. Suo Z, Avci R, Yang X, Pascual DW. Efficient immobilization and patterning of live bacterial cells. Langmuir. 2008;24(8):4161-7.

24. Wang J, Wu C, Hu N, Zhou J, Du L, Wang P. Micro-fabricated electrochemical cell-based biosensors for analysis of living cells in vitro. Biosensors. 2012;2(2):127-70.

25. Lisdat F, Schäfer D. The use of electrochemical impedance spectroscopy for biosensing. Anal Bioanal Chem. 2008;391(5):1555.

26. Macdonald JR. Impedance spectroscopy. Ann Biomed Eng. 1992;20(3):289-305.

Publisher's note Springer Nature remains neutral with regard to jurisdictional claims in published maps and institutional affiliations. 